\title{
A Preliminary Study on Application of Vibrating Device Instead of Topical Anaesthetic Gel During Injection of Local Anaesthesia
}

\author{
Meghana Reddy J' and Anjaneyulu K² \\ ${ }^{1}$ Saveetha Dental College and Hospitals, Saveetha Institute of Medical \\ and Technical Sciences (SIMATS), Saveetha University, Chennai 600077, India \\ ${ }^{2}$ Reader, Department of Conservative dentistry and Endodontics, Saveetha Dental College and Hospitals, \\ Saveetha Institute of Medical and Technical Sciences (SIMATS), Saveetha University Chennai 600077, India
}

\begin{abstract}
The "gate control" theory suggests pain can be reduced by simultaneous activation of nerve fibers that conduct nonnoxious stimuli. Local anaesthesia can be an anxiety inducing or a fearful experience. Vibration technique has been used for many years to reduce the pain. Patients were subjected to local anaesthetic injections after one of the following mucosal preparations. Three infiltration injections were given for each patient in three different quadrants between first and the second premolars. During the first injection direct infiltration was given without the application of topical anesthesia, then while injecting the second injection $20 \%$ benzocaine topical anesthesia was applied for 2 minutes and with application of vibrating stimulus the third infiltration was given. Patients were then given a score on the injection discomfort after each administration on a visual analogue scale. Statistical analysis was done using SPSS and Pearson chi-square test was performed. Results show that application of topical anaesthesia was better than vibrating device. Based on the results it is conclusive that the topical application is better than vibration stimulus.
\end{abstract}

KEY WORDS: VIBRATING DEVICE, LOCAL ANAESTHESIA, TOPICAL ANAESTHESIA.

\section{INTRODUCTION}

In dentistry managing pain and anxiety in patients has always been an essential part. To prevent pain, dentists must administer local anaesthesia (LA) via a needle injection. Anxiety and fear arise prior to or during the injection and remains as a barrier for many children and adults from receiving dental treatment. Therefore there

\section{ARTICLE INFORMATION}

*Corresponding Author: anji.tmdch@gmail.com

Received 13th June 2020 Accepted after revision 10th August 2020 Print ISSN: 0974-6455 Online ISSN: 2321-4007 CODEN: BBRCBA

Thomson Reuters ISI Web of Science Clarivate Analytics USA and Crossref Indexed Journal

\section{Clarivate
Analytics}

NAAS Journal Score 2020 (4.31) SJIF: 2020 (7.728)

A Society of Science and Nature Publication,

Bhopal India 2020. All rights reserved.

Online Contents Available at: http//www.bbrc.in/

Doi: http://dx.doi.org/10.21786/bbrc/13.7/72 is a constant search for newer techniques to alleviate the invasive and painful nature of the needle injection. In recent years, many researchers have developed alternative methods which can enable dental anaesthesia to be less invasive and more patient-friendly. The most common alternative methods in providing anaesthesia in dentistry are: topical anaesthesia, electronic dental anaesthesia, vibrating devices, jet-injectors, iontophoresis, and computerized control local anaesthesia delivery systems (Angelo and Polyvios, 2018).

Local anaesthesia can be an anxiety inducing or a fearful experience. Management of pain during the injection of Local anaesthesia is one of the most important steps in performing a dental treatment. Most of the painful dental treatments begin with Local anesthesia, so it is important to control the pain at this step (Ramezani et al., 2017). 
Pain in LA can occur due to mechanical trauma at the site of injection or due to rapid expansion of the tissue into which the anaesthetic solution is injected. Various methods like topical anaesthetics, slow infiltration, Transcutaneous electric nerve stimulation (TENS) and vibration can be used to reduce the pain (Ungor et al., 2014).

Topical local anaesthesia is given for various intraoral procedures like toothache, superficial mucosal lesions. They act by blocking the terminal fibres of sensory nerve endings, thus they control painful stimulation during needle insertion (Agarwal et al., 2017). Several indices can be used to measure the level of pain experienced during anesthetic injections. Level of anxiety should be determined before any intervention. Furthermore, many variables are involved in pain expression, and errors can occur in pain measurements. However, a VAS is a reliable tool for estimating levels of pain, assuming that it is correctly designed and the patients are thoroughly briefed about it (Price et al., 1983).

Vibration technique has been used for many years to reduce the pain (Smith et al., 2004; Nanitsos et al., 2009). It is one of the several nonpharmacological techniques used to reduce pain. Vibration was previously applied using a hand-held massager or a vibrating cotton swab. Generally vibration devices create vibrations that significantly decrease pain during needle insertion and the anesthetic injection in infiltration anesthesia of the maxilla and IANB of the mandible (Ghorbanzadeh et al., 2019). As the vibration of the hand-held massager cannot be monitored throughout, there may be variations in frequency and pressure applied from subject to subject over time (Reed, 2001; Johnson and Primosch, 2003; Nasehi et al., 2015).

Some of the newer local anesthetic delivery systems aimed at easing the fear of the needle take advantage of the gate control theory of pain management, which suggests that pain can be reduced by simultaneous activation of nerve fibers using vibration (Nusstein and Beck, 2003; Kuwahara and Ogawa, 2016). However, that pain reduction due to non-noxious touch or vibration can result from tactile-induced pain inhibition within the cerebral cortex itself and that the inhibition occurs without any contribution at the spinal level, including descending inhibitory actions on spinal neurons (Chaudhry et al., 2015; Ahmad and Mohmand, 2018).

We have numerous highly cited publications on well designed clinical trials and lab studies(Govindaraju, Neelakantan and Gutmann, 2017; Azeem and Sureshbabu, 2018; Jenarthanan and Subbarao, 2018; Manohar and Sharma, 2018; Nandakumar and Nasim, 2018; Teja, Ramesh and Priya, 2018; Janani and Sandhya, 2019; Khandelwal and Palanivelu, 2019; Malli Sureshbabu et al., 2019; Poorni, Srinivasan and Nivedhitha, 2019; Rajakeerthi and Ms, 2019; Rajendran et al., 2019; Ramarao and Sathyanarayanan, 2019; Siddique and Nivedhitha, 2019; Siddique et al., 2019; Siddique, Nivedhitha and Jacob, 2019). This has provided the right platforms for us to pursue the current study. The aim of the present study was to assess the application of vibrating device instead of topical anesthetic gel during injection of Local anesthesia.

\section{MATERIAL AND METHODS}

A preliminary study was done among 10 patients who visited the outpatient department at Saveetha Dental College. Patients were subjected to local anaesthetic injections after one of the following mucosal preparations. Three infiltration injections were given for each patient in three different quadrants between first and the second premolars. During the first injection direct infiltration was given without the application of topical anesthesia, then while injecting the second injection 20\% benzocaine topical anesthesia was applied for 2 minutes and with application of vibrating stimulus the third infiltration was given.

Local anesthesia administration: Infiltration was administered as injections for the maxilla and mandible. After each administration of local anaesthetic, patients were given a visual analogue scale where they gave a score on the injection discomfort. (Figure 1)

Figure 1: Visual Analogue Scale

0-10 Numeric Pain Rating Scale

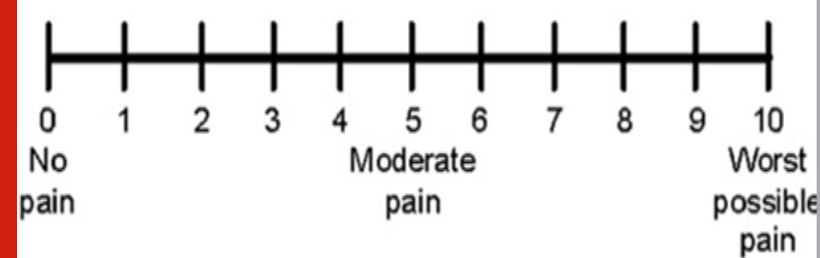

Figure 2: Application of vibration to the labial surface.

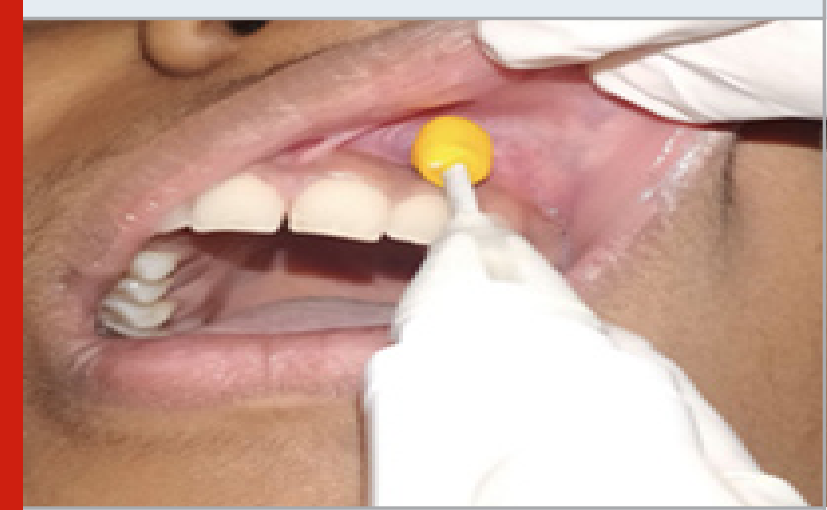

Figure 3: Waterpik Vibrator

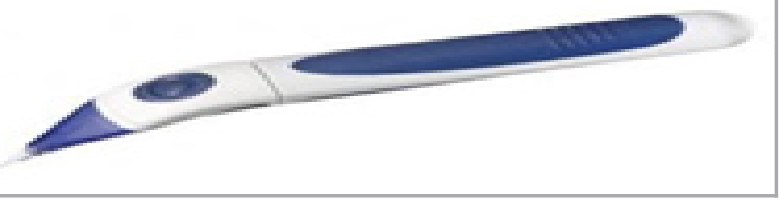


Statistical analysis: The data was exported to SPSS windows version 20 (IBM) for data checking. Data was sorted and represented in frequencies. Descriptive statistics and Pearson chi square test were performed on the tabulated values with the level of significance set at $<0.05$. The outcome was represented in bar graphs.

\section{RESULTS AND DISCUSSION}

Graph 1 shows the pain score on Visual Analogue Scale where pain was severe in Infiltration without topical anaesthesia with a mean score of 6.80 whereas in infiltration with topical anesthesia and infiltration with vibration the mean score was observed as 2.40 and 2.70 .

Graph 2 shows that on application of topical anaesthesia majority of the subjects had mild pain (60\%), while only $20 \%$ had moderate and severe pain. On direct Infiltration $60 \%$ of the subjects had moderate pain while only $20 \%$ of the subjects had mild and severe pain. On vibration stimulus all the subjects had moderate pain (100\%).

Graph 1: This graph shows the mean pain score comparison of all the 3 groups on Visual Analogue Scale. Infiltration without topical anesthesia (orange colour) has a mean pain score of 6.8 (Moderate pain), infiltration with topical anaesthesia (Yellow colour) has a mean pain score of 2.4 (Mild pain) and infiltration with vibration (Violet colour) with a mean pain score of 2.7 (mild pain). Infiltration without topic anaesthesia was observed to have more mean pain scores when compared with the other two groups.

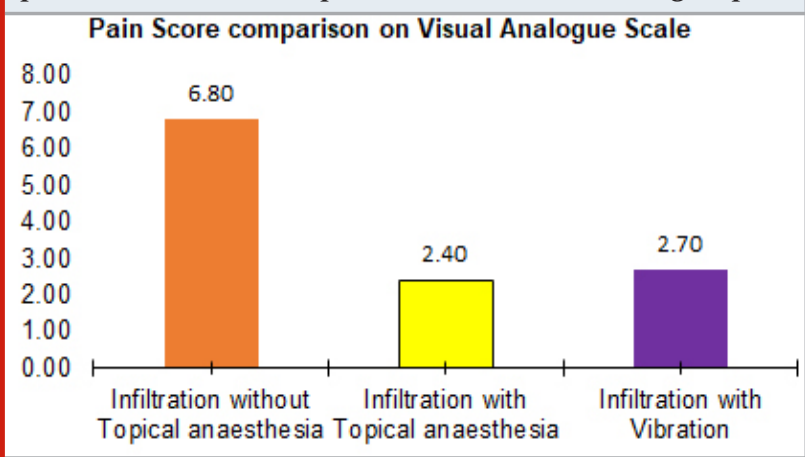

Dental anxiety and fear are the most frequent reasons preventing patients from dental visits and are usually scared of local anesthesia injections (Quarnstrom and Libed, 1994; Nanitsos et al., 2009; Suzuki et al., 2016; Ramezani et al., 2017). Hence, pain and anxiety control during local anesthetic injections is of significant clinical importance. Topical anesthetics numb the injection surface and provide pain relief on needle insertion, although there are other factors which should be controlled (Nanitsos et al., 2009).

Local anesthesia was given for a complete pain control. Although this method reduces the pain during needle insertion, total elimination of injection pain relies on causes like the amount, type, and injection speed of anesthesia plus the experience of the clinician. In addition, local anesthetics have narrow potential to enter deep into tissue. These might reduce the discomfort during insertion of the needle through the surface however, they are not as effective when the needle passes through deeper layers (Quarnstrom and Libed, 1994; Bonjar, 2011).

Graph 2: This graph shows association between the techniques of Local Anaesthesia and Pain perception using Visual Analogue Scale. The $\mathrm{X}$ axis shows the techniques of Local Anaesthesia and the $Y$ axis shows the pain perception on Visual Analogue Scale site in patients undergoing local anaesthesia.From this graph it is evident that "Infiltration with topical anesthesia" showed mild pain (Blue) when compared with the other groups. When infiltration was given along with the vibration the pain experienced by the patients was moderate (Red). It was observed that pain was severe (Green) when infiltration was done without topical anaesthesia and vibration. Pearson chi-square test was done (Table 1), $\mathrm{P}=0.001 \quad(<0.05$ - indicating statistically significant).

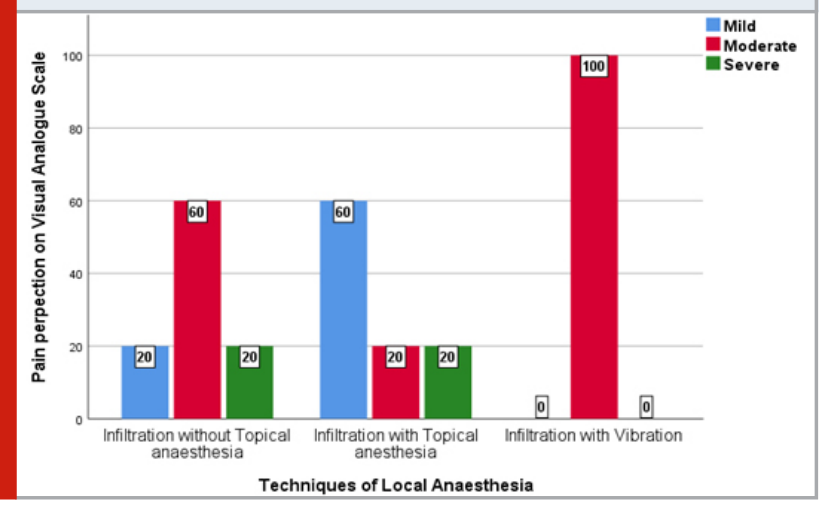

Table 1. Shows the Chi-Square test results for association between the techniques of Local Anaesthesia and Pain perception using Visual Analogue Scale.

\begin{tabular}{|l|c|c|c|}
\hline \multirow{2}{*}{} & \multicolumn{3}{|c|}{ Chi-Square Test } \\
\cline { 2 - 4 } & Value & df & $\begin{array}{c}\text { Asymptotic } \\
\text { significance } \\
\text { (2-sided) }\end{array}$ \\
\hline Pearson Chi-Square & $20.000 a$ & 18 & .001 \\
\hline Likelihood Ratio & 19.005 & 18 & .000 \\
\hline N of Valid Cases & 10 & & \\
\hline
\end{tabular}

Our results are similar to a study done by Saijo et al. (1995) who examined injection pain together with vibration of the site using VibraJect. They could not find significant differences between control and treatment groups (Saijo et al., 2005). However According to a study by Jayanthi et al., reported that the mean pain score during infiltration anesthesia of the maxilla and IANB of the mandible in children who received injections using DentalVibe was significantly lower than that in the control group (Jayanthi et al., 2015).Transmission 
of vibration signals through thick A-beta fibers versus pain signals through C fibers will make the sensory area of the brain release inhibitory neurotransmitters these and inhibit the activation of projection neurons within dorsal horn of spinal cord, leading to gate closure over pain stimuli. This is the reason vibration is used to reduce pain during many painful medical and dental procedures (Yenisey, 2009; Ungor et al., 2014).

Further studies are required on the efficacy of vibrations for pain control. For example, certain frequencies of the device may have a particularly high efficacy for pain control, a possibility that should be investigated in future studies. Furthermore, future studies should also investigate the role of related factors such as dental fear and anxiety, previous painful experiences, and the presence of dental pathologies(Ghorbanzadeh et al., 2019).

\section{CONCLUSION}

Within the limitations of this study it can be concluded that the Infiltration with topical application was better than Infiltration with vibration stimulus. Further studies with a larger sample size has to be done to confirm that vibration is effective during the injection of Local Anaesthesia.

\section{ACKNOWLEDGEMENTS}

The study was supported by Saveetha Dental College \& Hospitals, Saveetha Institute of Medical and Technical Sciences, Saveetha University, Chennai.

Conflict of Interest: There are no conflicts of interest as declared by the authors.

\section{REFERENCES}

Agarwal, N. et al. (2017) 'Effectiveness of Two Topical Anaesthetic Agents used along with Audio Visual Aids in Paediatric Dental Patients', Journal of clinical and diagnostic research: JCDR, 11(1), pp. ZC80-ZC83.

Ahmad, M. and Mohmand, M. H. (2018) 'Use of vibration anesthesia in hair restoration surgery', Journal of Pakistan Association of Dermatology, 27(3), pp. 247-251.

Angelo, Z. and Polyvios, C. (2018) 'Alternative practices of achieving anaesthesia for dental procedures: a review', Journal of Dental Anesthesia and Pain Medicine, p. 79. doi: 10.17245/jdapm.2018.18.2.79. Azeem, R. A. and Sureshbabu, N. M. (2018) 'Clinical performance of direct versus indirect composite restorations in posterior teeth: A systematic review', Journal of conservative dentistry: JCD, 21(1), pp. 2-9. Bonjar, A. H. S. (2011) 'Syringe micro vibrator (SMV) a new device being introduced in dentistry to alleviate pain and anxiety of intraoral injections, and a comparative study with a similar device', Annals of surgical innovation and research. Springer, 5(1), p. 1. Chaudhry, K. et al. (2015) 'Comparative evaluation of pain perception by vibrating needle (Vibraject) and conventional syringe anesthesia during various dental procedures in pediatric patients: A short study', International Dental \& Medical Journal of Advanced Research - VOLUME 2015, pp. 1-5. doi: 10.15713/ins. idmjar.5.

Ghorbanzadeh, S. et al. (2019) 'Effect of vibratory stimulation on pain during local anesthesia injections: a clinical trial', Restorative Dentistry \& Endodontics. doi: 10.5395/rde.2019.44.e40.

Govindaraju, L., Neelakantan, P. and Gutmann, J. L. (2017) 'Effect of root canal irrigating solutions on the compressive strength of tricalcium silicate cements', Clinical oral investigations, 21(2), pp. 567-571.

Janani, K. and Sandhya, R. (2019) 'A survey on skills for cone beam computed tomography interpretation among endodontists for endodontic treatment procedure', Indian journal of dental research: official publication of Indian Society for Dental Research, 30(6), pp. 834-838.

Jayanthi, M. et al. (2015) 'Effectiveness of new vibration delivery system on pain associated with injection of local anesthesia in children', Journal of Indian Society of Pedodontics and Preventive Dentistry, p. 173. doi: 10.4103/0970-4388.160343.

Jenarthanan, S. and Subbarao, C. (2018) 'Comparative evaluation of the efficacy of diclofenac sodium administered using different delivery routes in the management of endodontic pain: A randomized controlled clinical trial', Journal of conservative dentistry: JCD, 21(3), pp. 297-301.

Johnson, J. and Primosch, R. E. (2003) 'Influence of site preparation methods on the pain reported during palatal infiltration using the Wand Local Anesthetic System', American journal of dentistry, 16(3), pp. 165-169.

Khandelwal, A. and Palanivelu, A. (2019) 'Correlation Between Dental Caries And Salivary Albumin In Adult Population In Chennai: An In Vivo Study', Brazilian Dental Science, 22(2), pp. 228-233.

Kuwahara, H. and Ogawa, R. (2016) 'Using a Vibration Device to Ease Pain During Facial Needling and Injection', Eplasty, 16, p. e9.

Malli Sureshbabu, N. et al. (2019) 'Concentrated Growth Factors as an Ingenious Biomaterial in Regeneration of Bony Defects after Periapical Surgery: A Report of Two Cases', Case reports in dentistry, 2019, p. 7046203.

Manohar, M. P. and Sharma, S. (2018) 'A survey of the knowledge, attitude, and awareness about the principal choice of intracanal medicaments among the general dental practitioners and nonendodontic specialists', Indian journal of dental research: official publication of Indian Society for Dental Research, 29(6), pp. 716-720.

Nandakumar, M. and Nasim, I. (2018) 'Comparative evaluation of grape seed and cranberry extracts in preventing enamel erosion: An optical emission spectrometric analysis', Journal of conservative 
dentistry: JCD, 21(5), pp. 516-520.

Nanitsos, E. et al. (2009) 'The effect of vibration on pain during local anaesthesia injections', Australian dental journal, 54(2), pp. 94-100.

Nasehi, A. et al. (2015) 'Clinical pain evaluation with intraoral vibration device during local anesthetic injections', Journal of clinical and experimental dentistry, 7(1), pp. e23-7.

Nusstein, J. M. and Beck, M. (2003) 'Effectiveness of $20 \%$ benzocaine as a topical anesthetic for intraoral injections', Anesthesia progress, 50(4), pp. 159-163.

Poorni, S., Srinivasan, M. R. and Nivedhitha, M. S. (2019) 'Probiotic strains in caries prevention: A systematic review', Journal of conservative dentistry: JCD, 22(2), pp. 123-128.

Price, D. D. et al. (1983) 'The validation of visual analogue scales as ratio scale measures for chronic and experimental pain', Pain, pp. 45-56. doi: 10.1016/03043959(83)90126-4.

Quarnstrom, F. and Libed, E. N. (1994) 'Electronic anesthesia versus topical anesthesia for the control of injection pain', Quintessence international , 25(10), pp. 713-716.

Rajakeerthi, R. and Ms, N. (2019) 'Natural Product as the Storage medium for an avulsed tooth - A Systematic Review', Cumhuriyet Dental Journal, 22(2), pp. 249256.

Rajendran, R. et al. (2019) 'Comparative Evaluation of Remineralizing Potential of a Paste Containing Bioactive Glass and a Topical Cream Containing Casein Phosphopeptide-Amorphous Calcium Phosphate: An in Vitro Study', Pesquisa brasileira em odontopediatria e clinica integrada, 19(1), pp. 1-10.

Ramarao, S. and Sathyanarayanan, U. (2019) 'CRA Grid - A preliminary development and calibration of a paper-based objectivization of caries risk assessment in undergraduate dental education', Journal of conservative dentistry: JCD, 22(2), pp. 185-190.

Ramezani, G. H. et al. (2017) 'Effect of vibration on pain during Injection of local anesthesia: A split-mouth randomized clinical trial', Bioscience Biotechnology Research Communications, pp. 728-731. doi: 10.21786/ bbrc/10.4/18.

Reed, M. L. (2001) 'Surgical pearl: mechanoanesthesia to reduce the pain of local injections', Journal of the American Academy of Dermatology, 44(4), pp. 671-672.

Saijo, M. et al. (2005) 'Lack of pain reduction by a vibrating local anesthetic attachment: a pilot study', Anesthesia progress, 52(2), pp. 62-64.

Siddique, R. et al. (2019) 'Qualitative and quantitative analysis of precipitate formation following interaction of chlorhexidine with sodium hypochlorite, neem, and tulsi', Journal of conservative dentistry: JCD, 22(1), pp. 40-47.

Siddique, R. and Nivedhitha, M. S. (2019) 'Effectiveness of rotary and reciprocating systems on microbial reduction: A systematic review', Journal of conservative dentistry: JCD, 22(2), pp. 114-122.

Siddique, R., Nivedhitha, M. S. and Jacob, B. (2019) 'Quantitative analysis for detection of toxic elements in various irrigants, their combination (precipitate), and para-chloroaniline: An inductively coupled plasma mass spectrometry study', Journal of conservative dentistry: JCD, 22(4), pp. 344-350.

Smith, K. C. et al. (2004) 'Vibration anesthesia: a noninvasive method of reducing discomfort prior to dermatologic procedures', Dermatology online journal, 10(2), p. 1.

Suzuki, T. et al. (2016) 'Vibratory stimulation reduces superficial somatic pain of the finger: an experimental study', Chiba Igakkai zasshi. The Journal of Chiba Medical Society. 92(2), pp. 11-14.

Teja, K. V., Ramesh, S. and Priya, V. (2018) 'Regulation of matrix metalloproteinase-3 gene expression in inflammation: A molecular study', Journal of conservative dentistry: JCD, 21(6), pp. 592-596.

Ungor, C. et al. (2014) 'The effects of vibration on pain and anxiety during local anesthesia administration', JSM Dent, 2(1), p. 1022.

Yenisey, M. (2009) 'Comparison of the pain levels of computer-controlled and conventional anesthesia techniques in prosthodontic treatment', Journal of applied oral science: revista FOB, 17(5), pp. 414-420. 